Trabajo seleccionado para su publicación por el jurado del Premio Estudios Financieros, formado por: don Alfonso Aguiló Pastrana, doña Milagros Antón López, don Fernando Checa García, don Ángel de Miguel Casas, doña Laura Rayón Rumayor y don Javier Manuel Valle López.

\title{
Las redes como catalizadoras del germen emprendedor en la educación
}

\section{Sumario \\ 1. Alumnos nativos versus profesores inmigrantes \\ 2. Redes y startups en la educación \\ 3. Las redes y su aprovechamiento escolar \\ 4. Casos de éxito \\ 5. Conclusión: cómo fomentar la cultura emprendedora \\ 6. Bibliografía}

Fecha de entrada: 03-05-2018

Fecha de aceptación: 10-07-2018

\section{Extracto:}

Este trabajo parte de la hipótesis de que la consolidación de la era del conocimiento en tanto revolución industrial equiparable a las anteriores, marcada por el desarrollo tecnológico definido por la llamada «Web 2.0», el cambio profundo en los hábitos de un nuevo consumidor empoderado y protagonista, y una fuerte crisis económica y de modelo de los sistemas precedentes, encuentra fricciones con un sistema educativo conformado por «inmigrantes tecnológicos» que está formando a las nuevas generaciones de «nativos digitales». Las experiencias de aplicación de nuevos mecanismos de comunicación, como blogs, microblogs, wikis y redes sociales, a modelos culturales y educativos del pasado permiten prefigurar un escenario en el que la cultura de innovación, por presión de la demanda más que por la respuesta de la oferta, se convierta en vertebral del sistema educativo, sembrando el germen emprendedor en las nuevas generaciones. El trabajo se aproxima a los modelos de incubadoras y aceleradoras de startups, a algunos desarrollos de la regulación en España que marca el emprendimiento y las tecnologías de la información y la comunicación (TIC) como vertebrales, y a algunos casos de éxito, como referencias para un modelo de formación de emprendedores.

Palabras clave: educación digital, emprendimiento, cultura emprendedora, tecnologías de la información y la comunicación (TIC).

\footnotetext{
V. Núñez Fernández, profesor doctor de la Universidad a Distancia de Madrid (UDIMA) y director general de SchoolMarket.

2 F. Álvarez Cano, Máster en Finanzas por Deusto, diploma de estudios avanzados (DEA) y periodista por la Universidad Complutense de Madrid (UCM), experto en Comunicación por la Escuela de Formación Bancaria de Cecabank, profesor de Reputación Corporativa del Instituto de Estudios Bursátiles (IEB) y emprendedor en serie.
} 


\section{Social media as catalysts for entrepreneurship in education}

\begin{abstract}
:
This paper is based on the hypothesis that the consolidation of the knowledge age as an industrial revolution comparable to the previous ones, marked by the technological development defined by the so-called «Web $2.0 »$, the profound change in the habits of a new empowered and leading consumer, and a strong economic and model crisis of the previous systems, finds friction with an educational system made up of «technological immigrants» that is training the new generations of «digital natives». The experiences of applying new communication mechanisms such as blogs, microblogs, wikis and social networks to cultural and educational models of the past allow us to foreshadow a scenario in which the culture of innovation, under pressure from demand rather than from supply, becomes the backbone of the educational system, sowing the seeds of entrepreneurship in the new generations. The work focuses on the models of incubators and startup accelerators, some developments in regulation in Spain that mark entrepreneurship and information and communication technologies (ICT) as the backbone and some success stories as references for a model of entrepreneur training.
\end{abstract}

Keywords: digital education, entrepreneurship, entrepreneurship culture, information and communication technologies (ICT).

\section{Los estudiantes dominan el lenguaje digital de los ordenadores, videojuegos e internet, cuyos códigos se basan en colaborar, compartir y publicar}

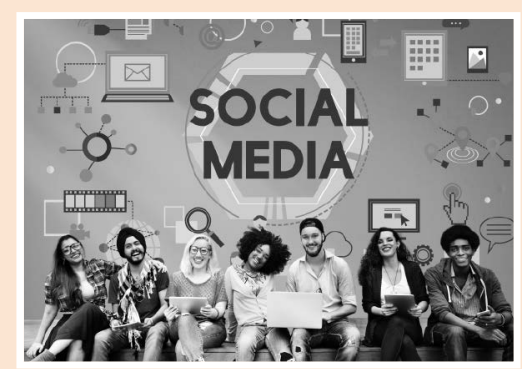

\section{ALUMNOS NATIVOS VERSUS PROFESORES INMIGRANTES}

El término «nativos digitales» fue acuñado por primera vez por Prensky en su artículo «Digital natives, digital immigrants» en 2001. En este artículo Prensky argumenta que hay una insalvable división que separa a los jóvenes, que han crecido con la tecnología digital al alcance de su mano, y a las personas más mayores, que se han convertido en usuarios de tecnología digital más adelante. Esta diferencia se observa muy claramente en el contexto educativo, en el que vemos enfrentados a los nativos digitales (alumnos) y a los inmigrantes digitales (sus profesores). Los nativos digitales han convertido las herramientas web en parte de su espacio natural de comunicación, como subraya Checa en su tesis Creación y transferencia de conocimiento mediante la utilización de tecnología Web 2.0: blogs y microblogs en el ámbito comunicativo ${ }^{3}$, lo cual ha cambiado la forma de acceder al aprendizaje. Los estudiantes dominan el lenguaje digital de los ordenadores, videojuegos e internet, cuyos códigos se basan en colaborar, compartir y publicar ${ }^{4}$, mientras que los profesores, que se han familiarizado más tarde con estas tecnologías, no tienen un dominio tan avanzado de las mismas. Prensky (2001) argumentó que, como resultado de la interacción con la tecnología, los nativos digi-

\footnotetext{
3 Véase diapositiva 4 en Checa (2010).

4 Véase nota 3.
} 
tales «piensan y procesan la información de un modo fundamentalmente diferente» a los inmigrantes digitales. Esta misma diferencia se ve entre alumnos y profesores.

Una aproximación muy similar a la de Prensky es la que Richard Gerver expuso al ser entrevistado por Eduardo Punset en el programa Redes ${ }^{5}$ :

«En su análisis, Gerver habló de la actual problemática entre docentes y alumnos, fruto de un abismo generacional que ha sido consecuencia de un fuerte cambio sociocultural sucedido en un breve espacio de tiempo y de forma exponencial» (Artero, 2011).

Los nativos digitales, de acuerdo con Prensky, procesan la información más rápido, disfrutan de las multitareas y de los videojuegos, mientras que los inmigrantes digitales procesan la información de un modo más lento, les confunde trabajar en más de una tarea a la vez y no aprecian estos acercamientos menos serios al aprendizaje. En su artículo de 2001 Prensky va un poco mas lejos y establece que los inmigrantes digitales tendrán siempre un «acento» al aprender este nuevo lenguaje, aunque más adelante reconocerá que las generaciones que no han nacido en la era digital pueden llegar a ser nativos digitales a través de la práctica y la experiencia con la tecnología. En esta división radica el problema fundamental de la educación actual. Los profesores deben cambiar su forma de enfocar la enseñanza con el objetivo de involucrarse e interactuar más con los estudiantes y los medios digitales.

Prensky argumenta en su artículo que los estudiantes de hoy no solo han cambiado gradualmente con respecto a los del pasado, al igual que otras generaciones anteriores cambiaban su forma de vestir o de hablar. En este caso se produce una discontinuidad muy grande, debido a la llegada y a la rápida difusión de las tecnologías digitales. Los estudiantes actuales representan las primeras generaciones que han crecido con esta tecnología, rodeados de todo tipo de objetos de la era digital, pasando miles de horas frente a un ordenador. Por esto, los estudiantes de hoy no son las personas para las que está enfocado el sistema

\footnotetext{
${ }^{5}$ Programa Redes, núm. 77 («Crear hoy escuelas para mañana»).
}

educativo. «Diferentes tipos de experiencias conducen a diferentes estructuras cerebrales», como dice el doctor Bruce D. Perry, del Baylor College of Medicine, a quien Prensky cita en su artículo para explicar que las formas y los patrones de pensamiento de los estudiantes de hoy han cambiado.

Como vemos, el problema radica en que los inmigrantes digitales hablan un lenguaje predigital y no valoran las nuevas capacidades y habilidades que desarrollan los estudiantes con respecto a la tecnología. Según el artículo de Prensky, no se entiende bien que los nativos digitales puedan aprender con éxito viendo la televisión o escuchando música, algo que los inmigrantes digitales no pueden hacer, ya que estas habilidades se desarrollan con los años de práctica que han tenido quienes han crecido paralelamente a la red y al desarrollo tecnológico digital. Prensky también habla sobre los trastornos de déficit de atención (TDA). Busca la razón por la que alumnos que han sido diagnosticados con TDA pueden prestar atención perfectamente a otro tipo de estímulos, como ver la televisión, o pueden pasarse horas con el ordenador, pero no son capaces de concentrarse en clase.

En unas jornadas organizadas por la Institución SEK en la Universidad Camilo José Cela, Prensky establecía que los estudiantes jóvenes están expuestos a millones de estímulos digitales y tecnológicos diariamente y que saben reaccionar a ellos, pero, cuando llegan al colegio, los reducen, aminoran su velocidad de actividad diaria tecnológica, forzándolos a razonar y pensar de una forma totalmente distinta a como ellos están acostumbrados y a la que en realidad les corresponde si tenemos en cuenta el momento en el que vivimos. En muchos casos esta transición a un modo de pensar arcaico no se consigue con éxito, lo que lleva al aburrimiento del alumno. Muchos no son capaces de hacer ese cambio, y eso conduce al tedio y a la falta de atención y de interés, lo que provoca el fracaso escolar. Por todo esto, Prensky establece que la introducción de la tecnología en el aula, para que los alumnos puedan «digerir la información» del mismo modo en que lo hacen durante su vida diaria, y la formación de los inmigrantes digitales para poder enfrentarse a este nuevo reto son dos elementos fundamentales para adaptar la educación a los nativos digitales.

Los educadores deben aprender a comunicarse en esta lengua digital, sin necesidad de cambiar lo que hasta 
ahora era importante o bueno, sino planteándose ir más rápido, abordando varias tareas en paralelo, tratando temas y contenidos nuevos que han de incluir todo lo que engloba la era digital. En su artículo, Prensky habla de la importancia de la formación en la robótica, el software, el hardware, etc., pero también habla de la importancia de la educación ética, política, de los idiomas, de la sociología, etc. Es necesario pensar en la forma de combinar estos contenidos para educar a los nativos digitales, «aprender nuevas maneras de hacer las cosas viejas» (Prensky, 2001, pp. 1-6). El éxito de un nuevo lenguaje educativo radica en la forma en que este se presente a los alumnos. Ejemplos de estos intentos de acercamiento los encontramos en los juegos de contenido escolar, en la clase de matemáticas en la que no solo te dejan usar la calculadora, sino en la que te explican cómo sacarle el máximo partido, o en las simulaciones históricas. Para llegar a los nativos digitales la forma de enseñar en la escuela de los inmigrantes digitales ha de cambiar y abrir sus puertas a la interactividad, combinada con la tecnología digital. Para Piscitelli (2001) (@piscitelli), profesor y filósofo argentino, y referencia mundial en aplicación de las TIC en educación, «hay que ir a buscar a los chicos donde ellos están: en Facebook, obviamente». Por supuesto quien dice Facebook dice Instagram, SnapChat o cualquier otra red social donde los nativos se encuentren.

Con el tiempo, la perspectiva de Prensky en 2001 se ha ido renovando, y esa división tan rígida entre nativos e inmigrantes no lo es tanto. Como hemos mencionado antes, en estudios posteriores, es el propio Prensky quien establece que, a través de la experiencia, los inmigrantes digitales pueden llegar a ser nativos digitales. En 2007, de acuerdo con un estudio de Bayne y Ross, los usuarios más frecuentes de internet no eran los jóvenes estudiantes, sino los pertenecientes a un rango de edad entre 35 y 44 años. Esto dice mucho del interés que la población adulta tiene por las tecnologías digitales. Por otro lado, en muchas familias, los ordenadores e internet se consideran valiosas herramientas de aprendizaje y los propios padres son quienes se ocupan de enseñar y fomentar su uso más allá del simple entretenimiento.

Por todo esto, vemos que es posible fomentar ese acercamiento de los inmigrantes digitales a las tec- nologías y que muchos de ellos pueden llegar a ser nativos digitales 0 incluso se consideran a sí mismos como tal. La tesis doctoral de Checa concluía ya en 2010 que es posible plantear un modelo de enseñanza-aprendizaje utilizando únicamente las herramientas Web 2.0, a pesar de que Bennet y Maton, en 2010, hablaran de que las encuestas sobre estudiantes daban como resultado que estos dedicaban su tiempo en internet, en su mayoría, a las redes sociales y no tanto a la creación de contenidos en blogs 0 wikis. Ambos enfoques, pioneros entonces, se han llevado a la práctica con éxito, como desarrollaremos posteriormente en una serie de casos prácticos. Como vemos, dentro de la multitud de actividades posibles, se pueden abarcar todos los ámbitos, y, dependiendo del enfoque de uso, conseguiremos unos objetivos u otros, ya que no es lo mismo el uso didáctico de las herramientas digitales que el uso para el propio ocio; hay tiempo para todo.

En las jornadas de la Institución SEK que mencionábamos anteriormente, según un artículo de la consultora educativa Ainhoa Marcos, publicado en el blog de SMART, Tecnología y Educación, fueron invitados 70 nativos digitales y 70 inmigrantes digitales (según la primera división estricta de Prensky, que considera a los nacidos antes de 1995 como inmigrantes digitales). El primer punto novedoso de todo esto es que es una de esas pocas veces que alumnos y profesores pueden hablar en igualdad de condiciones; algo que llama la atención, pero que es perfectamente lógico, porque ambos grupos son los que han de configurar la educación, trabajando colaborativamente.

No cabe duda de que los que ahora son considerados nativos digitales serán los próximos productores y consumidores (prosumers) y que existe la necesidad de intercomunicar ambos grupos, fusionarlos, en cierto modo, para intentar suturar la brecha digital acuñada por Prensky (2001), que advierte de la necesidad de realizar grandes cambios en los sistemas de formación actuales, porque, de lo contrario, afirma que "o los inmigrantes digitales aprenden a enseñar de manera distinta, o los nativos digitales deberán retroceder en sus capacidades cognitivas e intelectuales».

Esa necesidad de enseñar de otro modo se hace más necesaria hoy en día, pues, como se afirma en 
el informe «Educación digital y cultura de la innovación» (Núñez, Menor y Baeza, 2014), «una verdadera sociedad del conocimiento requiere personas "que conozcan", es decir, que muestren sensibilidad hacia el conocimiento y que demuestren poseer unos conocimientos mínimos y unas habilidades para el desempeño de sus tareas profesionales. En esta línea, es obvia la importancia de enseñar a los jóvenes a desear conocer, lo que les daría un nuevo y gratificante sentido a la adquisición de conocimientos, deseo del que en general carecen según la percepción de expertos responsables en recursos humanos de grandes compañías».

Para fomentar una cultura emprendedora entre los jóvenes de hoy, necesitamos reflejar sus modos de ver la tecnología y de usarla, y con ello fomentar los estímulos que sienten al recibir una educación dinámica e interactiva que refleje sus intereses e integre su velocidad de actividad digital en la educación. Esto les ayudará a aumentar su propia seguridad, ya que no se les obligará a cambiar su dinámica diaria,

\section{Para fomentar una cultura emprendedora entre los jóvenes de hoy, necesitamos reflejar sus modos de ver la tecnología y de usarla, y con ello fomentar los estímulos que sienten al recibir una educación dinámica e interactiva que refleje sus intereses e integre su velocidad de actividad digital en la educación}

sino a aprovecharla al máximo, lo que reduciría la falta de atención y los problemas de motivación, fomentando que se despierte la curiosidad por lo nuevo, mientras desarrollan intereses concretos que podrían definir su futuro.

\section{REDES Y STARTUPS EN LA EDUCACIÓN}

\subsection{La sociedad de la información y el fenó- meno startup}

La sociedad de la información puede definirse como «el campo de desarrollo social caracterizado por la capacidad de sus miembros (empresas, Administraciones públicas y ciudadanos) para obtener, compartir y procesar información por medios telemáticos instantáneamente, desde cualquier lugar y en la forma en que se prefiera» (Calvo, 2005, p. 6).

Segovia ${ }^{6}$ (2011), en su artículo «Las redes sociales: un reto para la escuela del siglo XX|», apunta lo siguiente:

«Las características de esta sociedad de la información han exigido un replanteamiento del concepto de "educación" como un proceso por el cual la persona adquiere una serie de competencias clave que le van a permitir

\footnotetext{
${ }^{6}$ Consultora educativa y autora de los libros Aplicación de las TIC a la docencia y Aplicación didáctica de las actividades de cinefórum, de Ideaspropias Editorial.
}

adaptarse de modo flexible a un mundo que está cambiando con rapidez y muestra múltiples interconexiones. Dos de estas competencias clave destacadas por el Parlamento y el Consejo Europeo son, en primer lugar, la competencia digital, basada en el uso de ordenadores para obtener, evaluar, almacenar, producir, presentar e intercambiar información, así como para comunicarse y participar en redes de colaboración a través de internet; $y$, en segundo lugar, la capacidad de aprender a aprender, es decir, la habilidad para iniciar el aprendizaje y persistir en él, para organizar su propio aprendizaje y gestionar el tiempo y la información eficazmente, ya sea individualmente 0 en grupos. En este sentido, poder contar con el potencial interactivo de las redes sociales en esta construcción del conocimiento es el primer paso para que los alumnos entren en contacto con las tecnologías de la información como herramientas didácticas». 


\section{Lo que hace de la eclosión de la sociedad de la información una verdadera revolución industrial [...] es la coincidencia de una revolución tecnológica (la Web 2.0), un cambio profundo en el comportamiento de los clientes [...] y una crisis económica y de modelo}

Lo que hace de la eclosión de la sociedad de la información una verdadera revolución industrial, equiparable a las dos anteriores, es la coincidencia de una revolución tecnológica (la Web 2.0), un cambio profundo en el comportamiento de los clientes (que han pasado de consumidores -meros receptores de información, productos y servicios-a prosumidores -productores de información y cocreadores de la experiencia de su propio consumo-), y una crisis económica y de modelo como la vivida desde 2007. Factores que se han dado en la última crisis, como muestra Álvarez (2017) en esta infografía (véase figura 1), y que prefiguran la respuesta desde la educación y la conformación de startups.

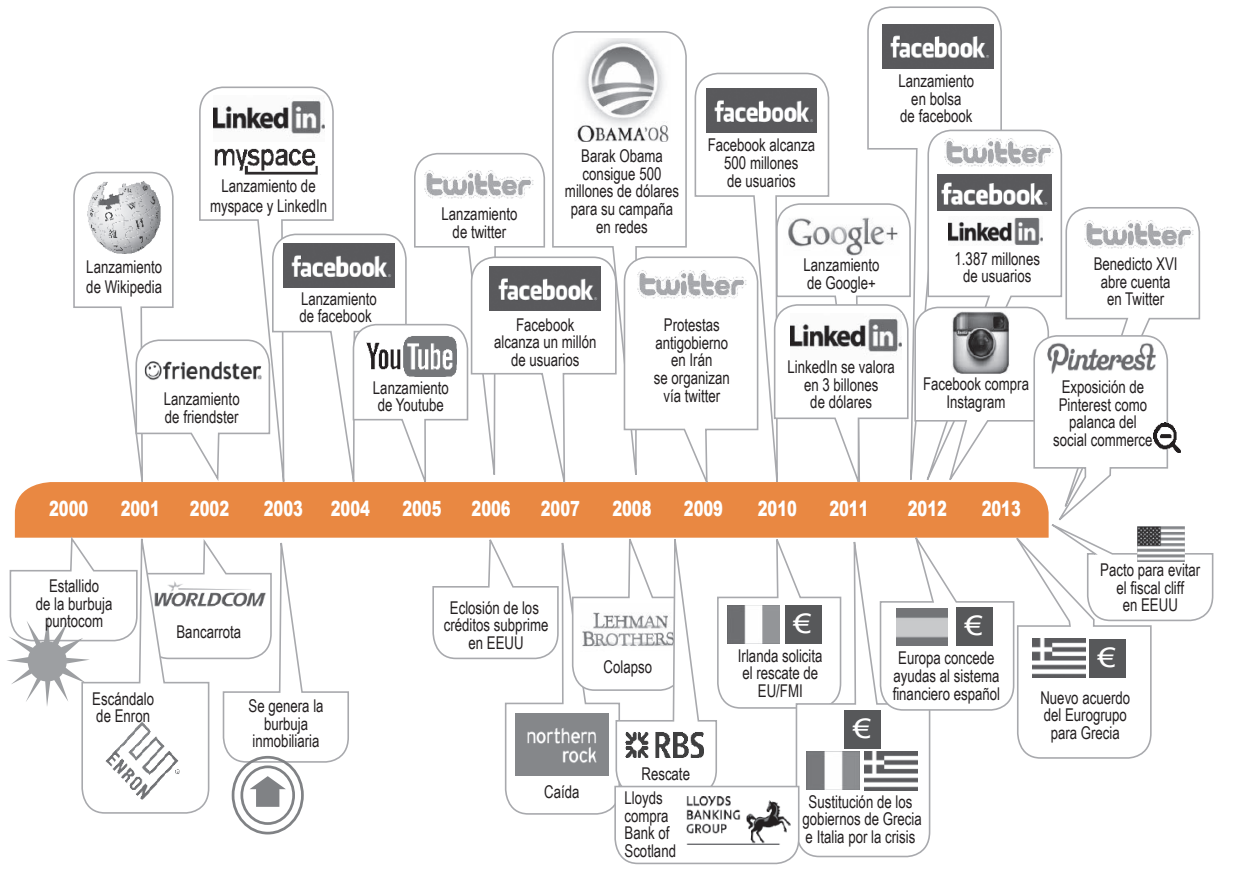


Precisamente, estos tres factores coadyuvan en la explosión de un nuevo tipo de empresas emergentes, las startups, llamadas así porque siguen los patrones del «ciclo de sobreexpectación» de Gartner en cuanto a su rápido crecimiento y escalabilidad de su modelo de negocio (véase figura 2 ).

Las startups difieren de otras empresas de nuevo cuño en su fuerte componente tecnológico (primera tendencia que comentábamos de la revolución del conocimiento), en su necesidad de financiarse (relacionado con la segunda tendencia, la crisis económica, que ha abocado a muchos jóvenes a emprender y ha posibilitado la ruptura del cuasi monopolio en financiación de la banca) y en poner el foco en el empoderamiento del

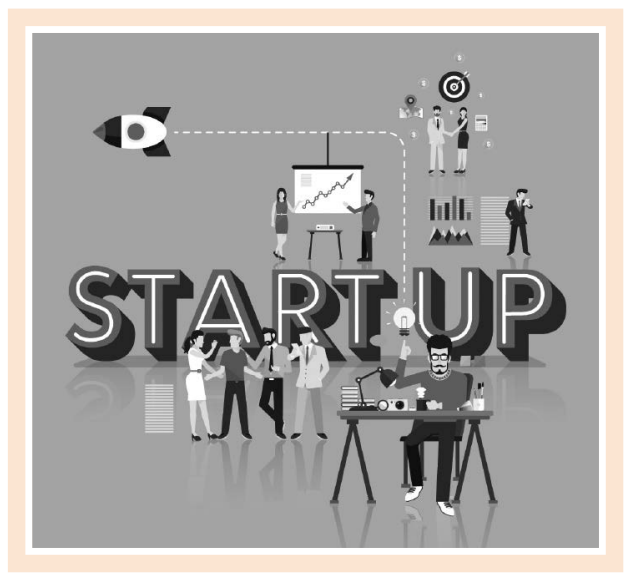

\section{Figura 2. Ciclo de sobreexpectación de Gartner}

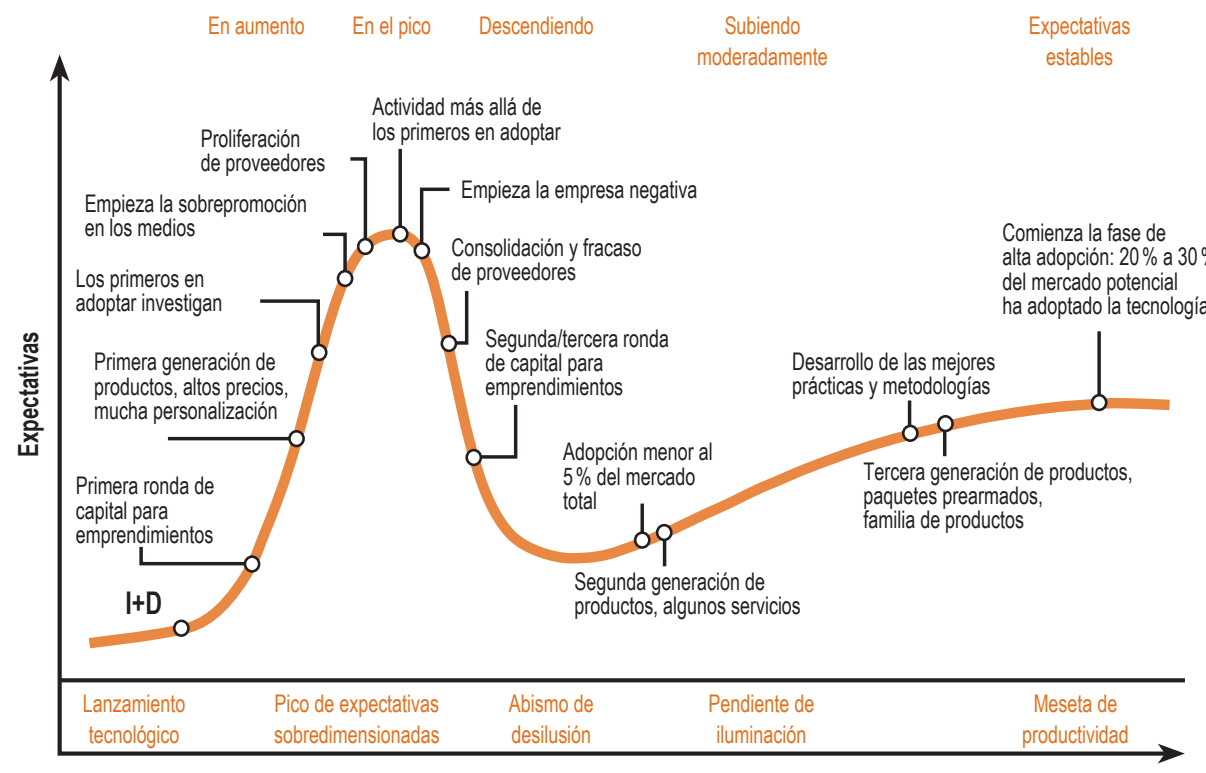

Tiempo 
cliente (relacionado con la tercera tendencia de cambio profundo de comportamiento en el consumidor). La evolución de las startups en España no ha cesado de crecer desde la crisis y, según algunos expertos, precisamente por la crisis (Delle, 2015). En el último Mobile World Congress ${ }^{7}$ celebrado en Barcelona pudimos conocer algunas cifras:

- En España compiten 3.258 startups, un $20 \%$ más que hace un año, con dos hubs o nichos principales (en Madrid y en Barcelona), de los 78 europeos, ocupando Barcelona y Madrid la quinta y sexta plazas continentales, respectivamente. El nuevo modelo de centros formativos superiores de alto rendimiento empieza a dar sus frutos.

- La educación concita el 5,9\% del total de startups existentes, por delante de las fintechs (nuevos competidores en el sector financiero) (véase figura 3).

- Nuestro país se ha convertido en el tercer destino que más talento emprendedor de competencias tecnológicas atrae, tras el Reino Unido y Alemania, y también en el cuarto que más exporta (tras el Reino Unido, Francia y Alemania), circunstancia que algunos expertos, como el presidente ejecutivo del Centro de Estudios Financieros, Roque de las Heras, explicaba así en una entrevista con el periódico El Economista (García, 2014):

\section{«¿Cree en la fuga de cerebros o en la mo- vilidad de cerebros?}

Son las dos caras de la misma moneda. Yo sí que creo que se trata de una fuga de talento alarmante para nuestro país. Por otro lado, desde el punto de vista de estos jóvenes, abrir el espectro de posibilidades y lanzarse a la aventura internacional es un reto que les va a enriquecer como personas y como profesionales. Lo que hay que procurar es trabajar para que la situación mejore a nivel interno, para que dentro de pocos años todo ese caudal de talento, enriquecido por la experiencia foránea, vuelva a España a seguir desarrollándose y a impulsar nuestro $1+D+i$.

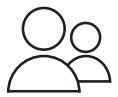

$18,3 \%$ Social

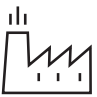

$16,1 \%$ Enterprise

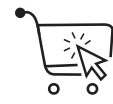

$14,7 \%$ e-Commerce

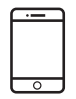

$12,8 \%$ Mobile

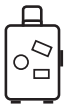

7,2\%

Tourism

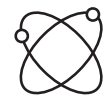

$7,1 \%$ Health \& Science

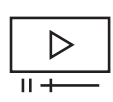

$6,7 \%$

Media

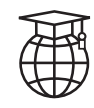

$5,9 \%$

Education

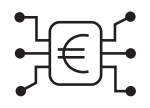

$\mathbf{5 , 5 \%}$

Fintech

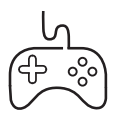

$1,7 \%$

Gaming

\section{0}

4,1\%

Others

Fuente: 〈http://www.awex.es/sites/default/files/Mobile_World_Capital_Barcelona_-_Digital_Startup_Ecosystem_Overview_2018.pdf>.

\footnotetext{
${ }^{7}$ Mobile World Capital Barcelona 2018: «Digital Startup Ecosystem Overview 2017».
} 
- España es el séptimo país con mayor número de desarrolladores tecnológicos (el 6,77 \% de la Unión Europea) y ocupa el tercer nivel por competitividad en costes en este sentido (cobran $40.000 €$ al año de media, solo por encima de los $38.000 €$ de Italia y de los $32.500 €$ de Grecia). Si somos los desarrolladores más eficientes, tendremos que formar a los desarrolladores del futuro (véase figura 4).

- El $80 \%$ de los españoles entre 20 y 30 años que encontrarán empleo en un futuro cercano lo harán en posiciones de sectores nuevos o emergentes, lo que ya está impactando en la oferta de planes de estudio (véase figura 5).

- España es el segundo país europeo que cuenta con mayor número de co-workings (centros de trabajo con espacios compartidos entre varias empresas, habitualmente startups). Nuestro país tiene un total de 129 co-workings, tras el Reino Unido, con 287 , y por delante de Italia (90), Francia (73) y Alemania (52).

\section{Figura 4 . Salario de los ingenieros informáticos (€laño)}

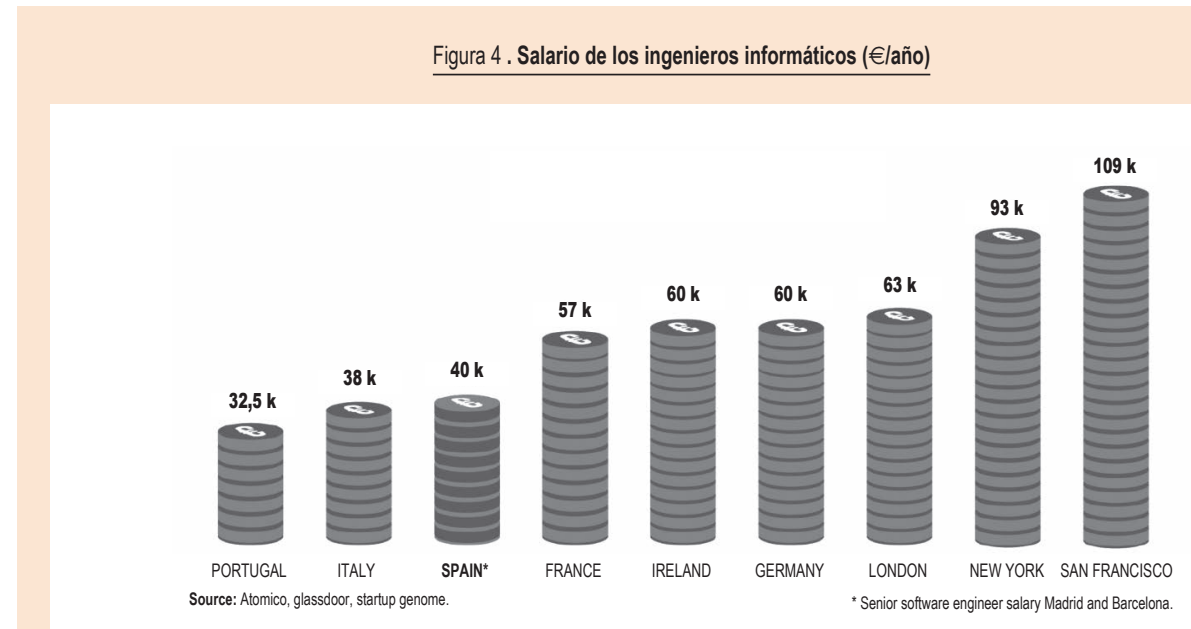

Figura 5. Motores tecnológicos del cambio

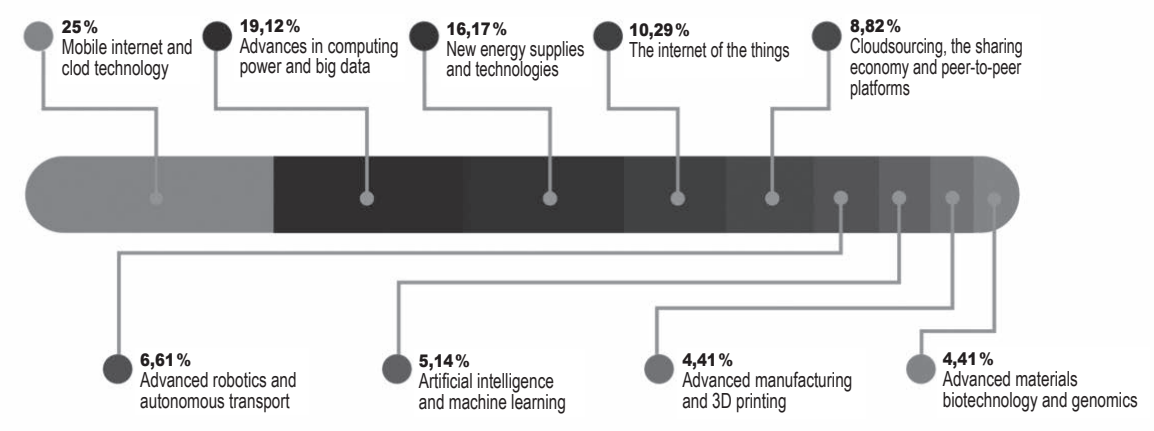

Fuente: <http://www.awex.es/sites/default/files/Mobile_World_Capital_Barcelona_-_Digital_Startup_Ecosystem_Overview_2018.pdf>. 
- Las inversiones de capital en España fueron de las que más crecieron en Europa en 2017, alcanzando 779,3 millones de euros, un $45 \%$ más que el año anterior. La media de inversión por ronda de financiación (3,64 millones) duplicó a la de 2016, posicionando a los hubs de Barcelona en quinta posición y a los de Madrid en novena posición por volumen de inversiones canalizadas y con 16 rondas (el doble que en 2016), superando los $10 \mathrm{mi}-$ llones de euros levantados (véase figura 6).

\subsection{El problema de la infoxicación}

Con la sociedad del conocimiento, aparece un problema básico, el exceso de información o infoxicación, lo que puede aumentar más las diferencias entre quienes saben discriminar y quienes no dominan la selección de información en un banco de datos tan grande como es internet, lo que abre oportunidades derivadas del llamado big data (como el aprendizaje adaptativo, la educación basada en competencias [EBC], el aula invertida, la gamificación y el aprendizaje móvil) (Inmediaciones, 2017):

- El aprendizaje adaptativo que utiliza, por ejemplo, la plataforma Knewtonse ${ }^{8}$, se aprovecha del big data para definir las necesidades particulares de cada alumno y diseñar su plan de estudios de forma personalizada, poniendo énfasis en aquellos aspectos en los que presenta debilidades a través de los canales (visuales, auditivos, kinestésicos) con los que aprenda mejor.

- La EBC relega el ritmo, la responsabilidad y la motivación en el alumno y se basa en la productividad y en el acceso al mercado laboral, cuyas demandas se incorporan de forma dinámica al programa formativo.

- El aula invertida es la base del blended-learning o formación web de los contenidos teóricos y de la aplicación práctica de los mismos en clases presenciales.

Figura 6. Inversiones de capital en España

Total capital invested

Deal count

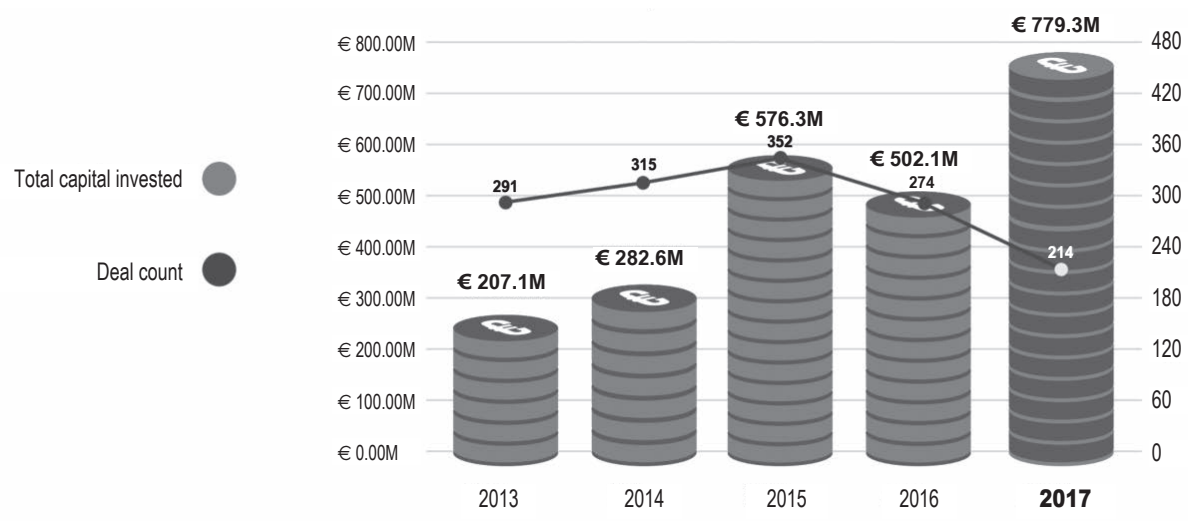

Fuente: <http://www.awex.es/sites/default/files/Mobile_World_Capital_Barcelona_-_Digital_Startup_Ecosystem_Overview_2018.pdf>.

\footnotetext{
$8<$ https://www.knewton.com/>.
} 
- La gamificación aplica la mecánica de los juegos al aprendizaje, multiplicando la motivación.

- El aprendizaje móvil o a través de aplicaciones instaladas por el alumno en su propio smartphone (ofrece cursos y material interactivo a través de los móviles en tiempo real).

Aparece también la inteligencia ambiental como una consecuencia directa de la exposición a las diferentes tecnologías de la información con las que interaccionamos. Pero el cambio se está produciendo tan rápidamente en todos los sectores que hace falta un análisis y una reflexión crítica que nos dejen valorar detalladamente las posibilidades y las limitaciones de esta sociedad.

Las escuelas se están preparando para estos nuevos retos educativos y los docentes deben estar dispuestos a afrontarlos, adecuándose a las nuevas demandas de la sociedad, formándose para que se desenvuelvan correctamente en el nuevo ambiente, integrando los nuevos tipos de educación combinada con las TIC y reevaluando los currículos tradicionales para que se adapten a la nueva sociedad de la información.

El impacto de esta nueva sociedad de la información en el mundo educativo se debe, en general, a que está impulsada por un rápido avance científico dentro del marco «socioeconómico global» y a que se sustenta en el uso y desarrollo de las TIC, lo que, según Marqués (2013), conlleva cambios que alcanzan todos los ámbitos de la actividad humana. Como es lógico, estos cambios se manifiestan también en el mundo docente y hacen necesaria una revisión de todo el sistema y de las instituciones educativas. Las formas de educar y aprender no pueden ser iguales y la organización global de la escuela y sus infraestructuras necesitan un cambio que les lleve a esta adaptación.

Aviram (2002) establece tres escenarios de las escuelas y centros docentes, en general, para adaptarse a las TIC y al nuevo contexto sociocultural:

- Escenario tecnócrata. En él, las escuelas se adaptan a las tecnologías a través de pequeños ajustes en los currículos dentro de lo que se conoce como «alfabetización digital» y en los que se incluiría «aprender sobre las $\mathrm{TIC}$ » $\mathrm{y}$ «aprender de las $\mathrm{TIC}$ ».

- Escenario reformista. Incluiría los otros dos niveles, y al que se le añadiría "aprender con las $\mathrm{TIC}$ »,

\section{Los alumnos recuerdan más lo que hacen con interés y lo que emprenden por sí mismos, por lo que la educación a través de las TIC puede promover el espíritu emprendedor de los jóvenes, dejando a un lado la clase magistral}

es decir, la introducción en la labor docente de nuevas metodologías constructivistas que supongan el uso de las TIC como instrumento cognitivo.

- Escenario holístico. En el que los centros hacen una apuesta en su totalidad, llevando a cabo una profunda reestructuración de todos sus elementos.

Este último es el cambio ideal para provocar una adaptación total de la escuela a las nuevas tecnologías digitales que definen la sociedad actual. Las TIC incorporan a las instituciones educativas una gran cantidad de información. La labor del sistema educativo será enseñar a seleccionar, interpretar y evaluar toda esta información que proviene de los nuevos medios. Es necesario formar en la selección y discriminación de la información, es decir, que los usuarios del medio sean capaces de discernir la información útil y verificable de la que no lo es, ya que la tecnología en sí misma no transforma la educación. Esta transformación depende de los usos y de las aplicaciones sobre los recursos didácticos. Las TIC se deben relacionar con los elementos curriculares y se hace de primera necesidad saber aplicarlas adecuadamente.

Una de las grandes ventajas de las TIC es la posibilidad de interactuar con los alumnos, con los materiales, con los recursos, etc. Se crea un nuevo entorno caracterizado por estar basado en una estructura no lineal, que permitirá presentar la información a los alumnos de una forma diferente. Pero, para que esto funcione, se necesita una actitud activa por parte del profesorado y del alumnado, ya que lo importante no es cuánta información nos llega, sino cómo interactuamos con ella y cómo la procesamos, dejando a un lado la actitud pasiva a la que estamos acostumbrados. 


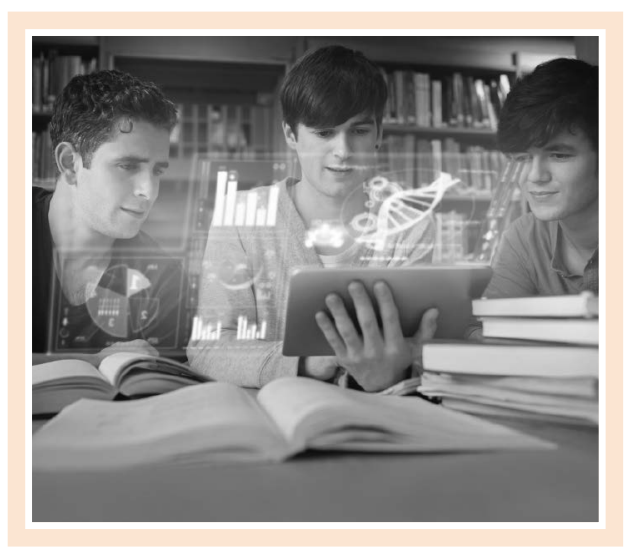

Los alumnos recuerdan más lo que hacen con interés y lo que emprenden por sí mismos, por lo que la educación a través de las TIC puede promover el espíritu emprendedor de los jóvenes, dejando a un lado la clase magistral. Se aprende haciendo (learning by doing), experimentando y disfrutando con el conocimiento adquirido. Como dice De las Heras (García, 2014), «me aseguraría de que esa cultura de emprendimiento que tanto echamos de menos en los jóvenes españoles estuviera ya presente en su educación desde edades tempranas. El germen emprendedor debe implantarse pronto. Solo así lograremos que los jóvenes dejen de ser emprendedores por obligación, como está sucediendo en gran medida ahora, y empiecen a serlo por vocación y sentimiento».

La flexibilidad espacio-temporal que ofrecen las TIC permite al estudiante elegir cuándo, dónde y cómo estudiar, ampliando el espacio educativo fuera de las aulas y fuera de una jornada tan estricta.

Las TIC permiten una ampliación del contexto educativo. El uso de las nuevas herramientas comunicativas amplía las formas de comunicación entre el profesor y el alumno, lo que implica nuevas posibilidades para la interacción didáctica, que podrá flexibilizarse de acuerdo a las necesidades del entorno. Todo esto conlleva un gran esfuerzo por parte del profesor, enfocado a crear nuevas estrategias educativas 0 a adecuar las existentes a esta forma de comunicación. Muchas veces se consideran las nuevas tecnologías como artificiales, cuando en realidad han sido creadas por y para las personas. La existencia de una tecnología que aglutina a las demás como lo es internet hace que no exista un medio mejor que otro, sino que la selección dependa de las necesidades del momento y de ciertos criterios, como objetivos, contenidos, características de los receptores, contexto, diferencias cognitivas, etc.

Uno de los mitos del uso de las TIC es que los profesores serán sustituidos por las tecnologías, cuando en realidad los profesores son los únicos capacitados para formar en las habilidades humanas y de aprendizaje básicas para el alumnado, por lo que hay que cambiar el rol del profesor, que pasa de ser un banco de información a enseñar cómo aprender. Los profesores, para implementar estas posibilidades que ofrecen las TIC, necesitarán de una formación permanente, ya que verán modificados y ampliados algunos de los roles que tradicionalmente han desempeñado. Pasarán a ser tutores virtuales y consultores de información. El esfuerzo viene a la hora de formarse y adaptarse a estos nuevos roles. Hay que tener en cuenta que las TIC no resuelven los problemas educativos, sino que son una herramienta de gran utilidad, y esta dependerá del uso concebido para ellas didácticamente. La presentación multimedia supone el paso de la elaboración de trabajos verbales y/o escritos a otros audiovisuales y multimedia, lo que repercute sobre el alumno y su actitud ante el trabajo.

Las TIC ofrecen a los docentes la posibilidad de replantearse las actividades tradicionales de enseñanza, para ampliarlas y complementarlas con nuevas actividades y recursos de aprendizaje. Desde los recursos digitales, como el software educativo, las comunidades virtuales o la posibilidad de crear tus propios métodos de trabajo. Por otro lado, propician la colaboración fuera del aula o de un colegio, ya que telemáticamente se puede trabajar con otras escuelas nacionales e internacionales, conectando a los alumnos y a los profesores y potenciando la educación intercultural a través de un conocimiento rápido y directo de lo que sucede en otras partes del mundo. El uso del software educativo permite el desarrollo de funciones muy positivas en la educación, desde funciones informativas a otras que fomentan la creatividad, la innovación o la expresión a través de nuevos medios. Para los nativos digitales esto motiva a la hora de enfrentarse a las tareas académicas, desarrolla un proceso continuo de trabajo intelectual, estimulando la iniciativa por parte del alumno (lo que aviva el espiritu emprendedor), fomenta el trabajo en grupo y colaborativo, y la adaptación a tareas dinámicas e interactivas. 
Como dice Martínez (2004), «para aprender es fundamental tener objetivos que cumplir y metas que alcanzar y, por lo tanto, es imprescindible la motivación y el interés». Esto es prácticamente lo mismo que se necesita para el desarrollo de un espíritu emprendedor y activo en los estudiantes. Hoy en día, el aprendizaje depende directamente de los profesores, y el uso de las redes sociales permite que todos colaboren en la educación, desde los padres a los propios alumnos. Los ordenadores nos facilitan el acceso a la información, y debemos enseñar a utilizarlo de forma que motive a los alumnos y se adapte al día a día de los nativos digitales. Por ejemplo, muchos jóvenes se inician en las nuevas tecnologías mediante los videojuegos, y esto puede ayudarnos a superar el reto de mantener a los alumnos interesados en lo que aprenden y en cómo lo aprenden.

Hay múltiples herramientas que pueden ayudar a crear actividades en el aula y que fomentan una educación más interactiva e interesante para los estudiantes. Algunas de ellas son las típicas presentaciones dinámicas, la creación de una web, de un blog o de un microblog con el contenido docente, que no solo tiene utilidad en la digitalización de los contenidos, sino que nos puede servir para alojar vídeos, audios o cualquier otro material atractivo para el alumnado. Otra opción es también la creación y el uso de libros virtuales. Tam-

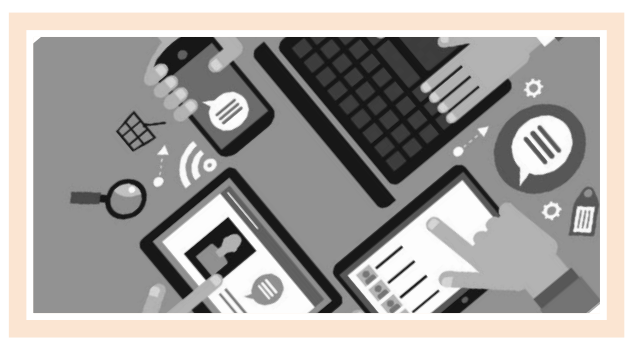

bién contamos con muchos tipos de actividades educativas 2.0, como talleres de juegos online y programas de aprendizaje virtual.

La educación debe adecuarse a los nuevos tiempos, haciendo el esfuerzo de integrar las TIC en el aula y, en algunos casos, compensando las necesidades que aún existen en el entorno. El acceso ilimitado a la información y el uso de nuevas tecnologías, como los ordenadores, son elementos muy motivadores para el alumnado, por lo que favorecen un aprendizaje significativo y permiten la atención a la diversidad, favoreciendo el progreso individual de los alumnos. A pesar de las dificultades que pueda haber para integrar las TIC en la escuela, son imprescindibles para el desarrollo adecuado de la educación en los alumnos actuales, los llamados nativos digitales.

\subsection{El emprendimiento como elemento transversal: LOMCE y FP}

La Ley orgánica 8/2013, de 9 de diciembre, para la mejora de la calidad educativa (LOMCE), incorpora y dota de peso específico al emprendimiento:

\section{- El emprendimiento como objetivo:}

- En primaria (art. 17): «b) Desarrollar hábitos de trabajo individual y de equipo, de esfuerzo y de responsabilidad en el estudio, así como actitudes de confianza en sí mismo, sentido crítico, iniciativa personal, curiosidad, interés y creatividad en el aprendizaje, y espíritu emprendedor».

- En secundaria (art. 23): «g) Desarrollar el espíritu emprendedor y la confianza en sí mismo, la participación, el sentido crítico, la iniciativa personal y la capacidad para aprender a aprender, planificar, tomar decisiones y asumir responsabilidades».
- En bachillerato (art. 33): «k) Afianzar el espíritu emprendedor con actitudes de creatividad, flexibilidad, iniciativa, trabajo en equipo, confianza en uno mismo y sentido crítico».

- En formación profesional (FP) (art. 40): «h) Afianzar el espíritu emprendedor para el desempeño de actividades e iniciativas empresariales».

- El emprendimiento como elemento transversal (al igual que las nuevas tecnologías). En su artículo 18, para primaria, y en los artículos 24 y 25 , para secundaria, la LONCE establece el emprendimiento, junto a la comprensión lectora, la expresión oral y escrita, la comunicación audiovisual, las TIC y la educación cívica y constitucional, como elementos que deberían trabajarse en todas las áreas. 
- El emprendimiento como competencia. Se desarrolla en la Orden ECD/65/2015:

\section{«6. Sentido de iniciativa y espiritu emprendedor}

La competencia sentido de iniciativa y espíritu emprendedor implica la capacidad de transformar las ideas en actos. Ello significa adquirir conciencia de la situación a intervenir 0 resolver, y saber elegir, planificar y gestionar los conocimientos, destrezas o habilidades y actitudes necesarios con criterio propio, con el fin de alcanzar el objetivo previsto.

Esta competencia está presente en los ámbitos personal, social, escolar y laboral en los que se desenvuelven las personas, permitiéndoles el desarrollo de sus actividades y el aprovechamiento de nuevas oportunidades. Constituye igualmente el cimiento de otras capacidades y conocimientos más específi$\cos$, e incluye la conciencia de los valores éticos relacionados.

La adquisición de esta competencia es determinante en la formación de futuros ciudadanos emprendedores, contribuyendo así a la cultura del emprendimiento. En este sentido, su formación debe incluir conocimientos y destrezas relacionados con las oportunidades de carrera y el mundo del trabajo, la educación económica y financiera o el conocimiento de la organización y los procesos empresariales, así como el desarrollo de actitudes que conlleven un cambio de mentalidad que favorezca la iniciativa emprendedora, la capacidad de pensar de forma creativa, de gestionar el riesgo y de manejar la incertidumbre. Estas habilidades resultan muy importantes para favorecer el nacimiento de emprendedores sociales, como los denominados intraemprendedores (emprendedores que trabajan dentro de empresas u organizaciones que no son suyas), así como de futuros empresarios.

Entre los conocimientos que requiere la competencia sentido de iniciativa y espíritu emprendedor se incluye la capacidad de reconocer las oportunidades existentes para las actividades personales, profesionales y comerciales. También incluye aspectos de mayor amplitud que proporcionan el contexto en el que las personas viven y trabajan, tales como la comprensión de las líneas generales que rigen el funcionamiento de las sociedades y las organizaciones sindicales y empresariales, así como las económicas y financieras; la organización y los procesos empresariales; el diseño y la implementación de un plan (la gestión de recursos humanos y/o financieros); asi como la postura ética de las organizaciones y el conocimiento de cómo estas pueden ser un impulso positivo, por ejemplo, mediante el comercio justo y las empresas sociales.

Asimismo, esta competencia requiere de las siguientes destrezas o habilidades esenciales: capacidad de análisis; capacidades de planificación, organización, gestión y toma de decisiones; capacidad de adaptación al cambio y resolución de problemas; comunicación, presentación, representación y negociación efectivas; habilidad para trabajar, tanto individualmente como dentro de un equipo; participación, capacidad de liderazgo y delegación; pensamiento crítico y sentido de la responsabilidad; autoconfianza, evaluación y autoevaluación, ya que es esencial determinar los puntos fuertes y débiles de uno mismo y de un proyecto, así como evaluar y asumir riesgos cuando esté justificado.

Finalmente, requiere el desarrollo de actitudes y valores, como la predisposición a actuar de una forma creadora e imaginativa; el autoconocimiento y la autoestima; la autonomía o independencia, el interés y esfuerzo y el espíritu emprendedor. Se caracteriza por la iniciativa, la proactividad y la innovación, tanto en la vida privada y social como en la profesional. También está relacionada con la motivación y la determinación a la hora de cumplir los objetivos, ya sean personales o establecidos en común con otros, incluido el ámbito laboral.

Así pues, para el adecuado desarrollo de la competencia sentido de la iniciativa y espíritu emprendedor resulta necesario abordar:

- La capacidad creadora y de innovación: creatividad e imaginación; autoconocimiento y autoestima; autonomía e independencia; interés y esfuerzo; espíritu emprendedor; iniciativa e innovación. 
- La capacidad proactiva para gestionar proyectos: capacidad de análisis; planificación, organización, gestión y toma de decisiones; resolución de problemas; habilidad para trabajar tanto individualmente como de manera colaborativa dentro de un equipo; sentido de la responsabilidad; evaluación y autoevaluación.

- La capacidad de asunción y gestión de riesgos y manejo de la incertidumbre: comprensión y asunción de riesgos; capacidad para gestionar el riesgo y manejar la incertidumbre.

- Las cualidades de liderazgo y trabajo individual y en equipo: capacidad de liderazgo y delegación; capacidad para trabajar individualmente y en equipo; capacidad de representación y negociación.

- Sentido crítico y de la responsabilidad: sentido y pensamiento crítico; sentido de la responsabilidad».

- El emprendimiento como asignatura. Asignatura optativa en educación secundaria obligatoria (ESO), dentro del bloque de asignaturas específicas, denominada «Iniciación a la Actividad Emprendedora y Empresarial».

El Gobierno de Aragón, entre sus perfiles desarrollados para educación primaria ${ }^{9}$, propone una serie de perfiles competenciales vinculados a trabajos concretos en clase:

- CN.1.5.2. Realiza un proyecto, trabajando de forma individual o en equipo, y presenta un informe, utilizando soporte papel y/o digital, recogiendo información de diferentes fuentes (directas, libros, internet, etc.), con diferentes medios, y comunicando de forma oral la experiencia realizada, apoyándose en imágenes, textos escritos en Word y/o PowerPoint.

- MAT.1.4.2. Se plantean nuevos problemas, a partir de uno resuelto, variando los datos, proponiendo nuevas preguntas, conectándolo con la realidad, buscando otros contextos, etc.

- MAT.1.5.1. Elabora informes en diferentes soportes (presentaciones, gráficos, textos, etc.) sobre el proceso de investigación realizado a partir de cuestio-

\footnotetext{
${ }^{9}$ Perfiles competenciales (anexo II) del Gobierno de Aragón.
}

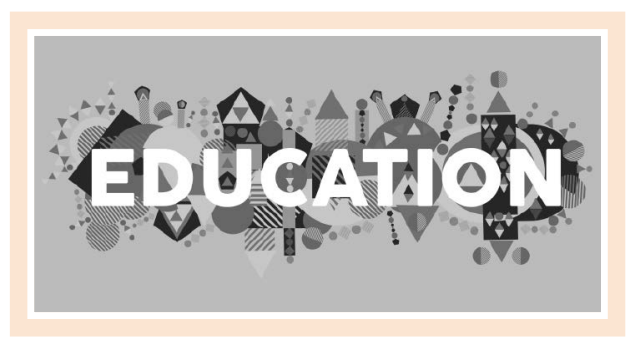

nes concretas de carácter matemático sobre el entorno inmediato, exponiendo las fases del mismo y valorando, con la ayuda de pautas definidas, los resultados y las conclusiones obtenidas.

- LCL.1.11.4. Prepara reportajes sobre temas de interés cercanos.

- LCL.3.1.3. Escribe diferentes tipos de textos adecuando el lenguaje a las características más básicas del tipo de texto (notas, felicitaciones, invitaciones, etc.), siguiendo modelos o copiando al dictado.

- CN.5.2.1. Construye alguna estructura sencilla que cumpla una función o condición para resolver un problema a partir de piezas moduladas (escalera, puente, tobogán, etc.).

En el aula, el desarrollo de este impulso legislativo se ha derivado hacia el aprendizaje basado en proyectos $(\mathrm{ABP})$, a partir del aprendizaje experimental, como en el programa Miniempresa Educativa ${ }^{10}$ de la Junta de Andalucía, basado en talleres, ferias y cursos de formación del profesorado, o en la propuesta didáctica del Programa Agrega sobre educación emprendedora para $5 .^{\circ} \mathrm{de}$ primaria $^{11}$, también de la Junta de Andalucía. Por su parte, el Ministerio de Educación y Formación Profesional ${ }^{12}$ proporciona recursos, formación específica y materiales vinculados al desarrollo del emprendimiento en la FP. Destaca en este sentido el proyecto IncuVET ${ }^{13}$, financiado por la Unión Europea, que promueve la función de los centros de FP como nodos de emprendimiento a nivel local y regional para crear valor.

\footnotetext{
$10<$ http://www.juntadeandalucia.es/AndaluciaEmprende/miniempresaeducatival>

11 <http://agrega.juntadeandalucia.es/visualizador-1/Visualizar/Visualizar. do?identificador=es-an_2013111913_9130331\&secuencia=false\&idioma=es >.

$12<$ http://www.todofp.es/profesores/formacion-innovacion/emprendimiento-en-fp.html>.

$13<$ <ttp://www.incuvet.eu/es/>.
} 


\section{LAS REDES Y SU APROVECHAMIENTO ESCOLAR}

El papel de los educadores se basa en enseñar a los alumnos a aprender, y más concretamente a aprender a pensar por sí mismos, mediante dos papeles básicos, ofrecer una retroalimentación adecuada y manejar y reforzar las relaciones interpersonales. Estos dos roles son los que más se potencian a través de las redes sociales, ya que facilitan la interacción entre centros escolares, profesores, padres y alumnos, así como con personas procedentes de todas partes del mundo, contribuyendo a formar un diálogo educativo eficiente y dejando a un lado el monólogo clásico de los profesores. Favorecemos por tanto las relaciones interpersonales y motivamos la participación de los alumnos en su propia formación.

Las redes sociales o comunidades virtuales ayudan a conseguir, además, una retroalimentación efectiva. El filósofo John Dewey dijo que «la educación no es un asunto de narrar y escuchar, sino un proceso activo de construcción; es un principio tan aceptado en la teoría como violado en la práctica». Esto nos revela que, aunque se sepa que la labor principal de un docente es la de ofrecer el feedback adecuado, bien por falta de recursos, bien por falta de interés del alumnado, si este se encuentra desmotivado y sin retos que alcanzar, esta labor no se lleva a cabo adecuadamente. A través de las redes sociales facilitamos esta tarea, ya que el alumno participa más, no tiene que levantar la mano en clase, tiene un tiempo extra para la reflexión y para analizar respuestas, y, además, queda un registro escrito susceptible de ser consultado en cualquier momento. Las redes sociales son una herramienta ideal para ofrecer un feedback personalizado y constructivo a través del cual el alumno se proponga practicar las tareas reales. Se aprende haciendo.

La labor del docente conlleva un componente humano que los ordenadores no pueden alcanzar. Si el educador se especializa en aquello en lo que consiga ser mejor que los ordenadores, su labor se centrará en formar a los alumnos en los aspectos en los que estos tengan que enfrentarse día a día, como, por ejemplo, cómo aprender a desenvolverse en la sociedad o cómo manejar el estrés. La educación debe fomentar un diálogo entre profesores y alumnos que muchas veces no puede darse en un aula. Los docentes van a empezar a gestionar personas y sus consecuentes relaciones, ayudando a los alumnos en sus relaciones interpersonales, que, al fin y al cabo, es lo que define a las personas, y ampliándolas para que puedan llegar al conocimiento. Como dijeron Les Luthiers, «lo importante no es saber, sino tener el teléfono del que sabe».

Basándonos en un artículo de Martínez (2004), titulado «El papel del tutor en el aprendizaje virtual», podemos decir que colaborar y cooperar con nuestros contactos da valor a las tareas realizadas, por lo que es la calidad de las relaciones establecidas lo que definirá la calidad del aprendizaje:

«El aprendizaje, la colaboración o la confianza no suceden sin más y de manera automática. Hay que provocarlo, inducirlo, alimentarlo, fomentarlo, crear las condiciones idóneas para que ocurra y, sobre todo, mimarlo y cuidarlo para que se perpetúe. Para lograrlo, el tutor tiene que desarrollar esa labor intangible, guiando a los alumnos hacia los recursos, hacia los contenidos, hacia los expertos».

Este es el beneficio de las redes sociales. Ayudan a perpetuar relaciones y a acceder de un modo directo a información y recursos que, de no ser así, no podríamos alcanzar.

Debemos aprender a enseñar a través del uso de las redes sociales para obtener resultados. Desde siempre, el conocimiento se trasmite a través de la comunidad y ahora podemos acceder a ellas virtualmente, manteniendo viva la capacidad de motivación e interacción con los jóvenes, quienes dominan a la perfección su uso. Muchos entornos educativos han creado redes internas de comunicación, como, por ejemplo comunidades, chats, tutores o bibliotecas virtuales. Este tipo de acciones se llevan ya a cabo en todas las etapas educativas. Pero debemos tener en cuenta que, por pertenecer a estas comunidades virtuales, el conocimiento y el aprendizaje no suceden automáticamente, sino que debemos fomentar la integración mediante técnicas docentes, como la solución de problemas prácticos, para alcanzar el conocimiento.

Con el uso de las redes sociales en la escuela, la construcción compartida del conocimiento a través de una 
comunidad virtual tampoco es perfecta, ya que suele haber un grupo que impone sus conocimientos al resto, pero esto también sucede en las aulas, donde siempre hay alumnos más participativos tanto en las actividades más teóricas como en los debates y en las actividades prácticas. Se necesita fomentar y reforzar la participación de cada individuo, por ejemplo, mediante unos mínimos de participación evaluables al año. Si se hace un foro de discusión, hay que establecer un mínimo de puntos, sobre el total, que provengan de la participación en ese foro en concreto; una actividad académica dirigida más. El mundo avanza e innova gracias a los que crean. Las personas con decisión y creativas son los futuros emprendedores, y son los docentes quienes tienen que dar el gran paso para animar a los estudiantes a crear. Las redes sociales se han convertido en una gran herramienta para la creación, la interactividad y la creatividad. El alumno, por lo general, desarrolla una serie de habilidades que son las que le ayudan a aprender; la realización de análisis, síntesis y formulación de hipótesis. Mediante este tipo de habilidades los alumnos aprenden de un modo mucho más rápido y eficiente que si solo aprendiesen a memorizar, sobre todo si tenemos en cuenta que recordamos más lo que aprendemos de forma positiva y por interés propio. Como explica Martínez (2004), «el aprendizaje es un fenómeno social que ocurre en el ámbito personal $y$, como tal, es intransferible». Se aprende haciendo, practicando y experimentando, y, por lo general, hacemos lo que interesa, lo que nos motiva y lo que despierta nuestra atención, ya que lo que se aprende está unido al cómo se aprende y «la experiencia activa la construcción del conocimiento» (Martínez, 2004). El uso de herramientas virtuales puede ayudar a poner en práctica ese conocimiento (el cual, si solo lo aprendemos de memoria, no tiene apenas utilidad) y a fomentar el aprendizaje colectivo y la colaboración, sobre todo con el tráfico de información.

El espíritu emprendedor viene dado por este tipo de aprendizaje, un aprendizaje que fomente la creatividad, la independencia y la libertad de ideas, mediante una educación dinámica e interactiva, adaptada al lenguaje y a la forma de trabajo de los nativos digitales. La falta de motivación en la educación es lo que muchas veces hace que el espíritu emprendedor no se desarrolle, y, para motivar, es necesario que el alumno no se aburra y que se sienta identificado con la educación que recibe; por eso, es necesario la integración de las TIC en la educación. Las redes sociales son un entorno muy eficaz a la hora de desarrollar estas habilidades, ya que convierten al estudiante en protagonista activo de su propia formación.

\subsection{Emprendimiento 2.0 en la escuela 2.0}

La enseñanza 2.0 en la escuela 2.0 debe tener en cuenta el uso que sus alumnos hacen de la tecnología, valorar los recursos económicos y buscar la mejor forma de integrar las TIC en el contexto educativo. AulaPlaneta propone algunas fórmulas sencillas:

- Estimular el debate en Facebook.

- Jugar a las adivinanzas en Twitter.

- Dar una clase virtual en YouTube Live (antiguo Google Hangouts).

- Trabajar la comunicación visual y la creatividad con Instagram.

- Crear un repositorio de webs interesantes vía RSS (really simple syndication) con Feedly.

- Proponer un tablero colaborativo en Pinterest.

La escuela 2.0 es algo más que la simple digitalización de los contenidos educativos y la conectividad en los colegios; es la escuela del futuro. Una revolución que va más allá de la dotación de un ordenador por alumno que planteaba el Gobierno hace unos años. Comprende un cambio en todo el sistema de enseñanza para lograr una educación 2.0. Un cambio que ya hemos tratado a lo largo de este trabajo, y que surge desde los docentes y afecta a todo el tratamiento del contenido. Esto quiere decir que para que todo funcione adecuadamente es necesario formar al personal docente y dotar a las escuelas de las infraestructuras necesarias. Para esto se necesita un plan muy deta-

La enseñanza 2.0 en la escuela 2.0 debe tener en cuenta el uso que sus alumnos hacen de la tecnología, valorar los recursos económicos y buscar la mejor forma de integrar las TIC en el contexto educativo 
llado e intenso. La revista digital Edudemic, especializada en TIC aplicadas a la educación, va un poco más allá: propone utilizar las redes como herramienta do- cente y menciona canales como YouTube, Facebook, Twitter y Pinterest con recursos para educadores ${ }^{14}$ (véase figura 7).

\section{Social Media for Teachers Instructor}

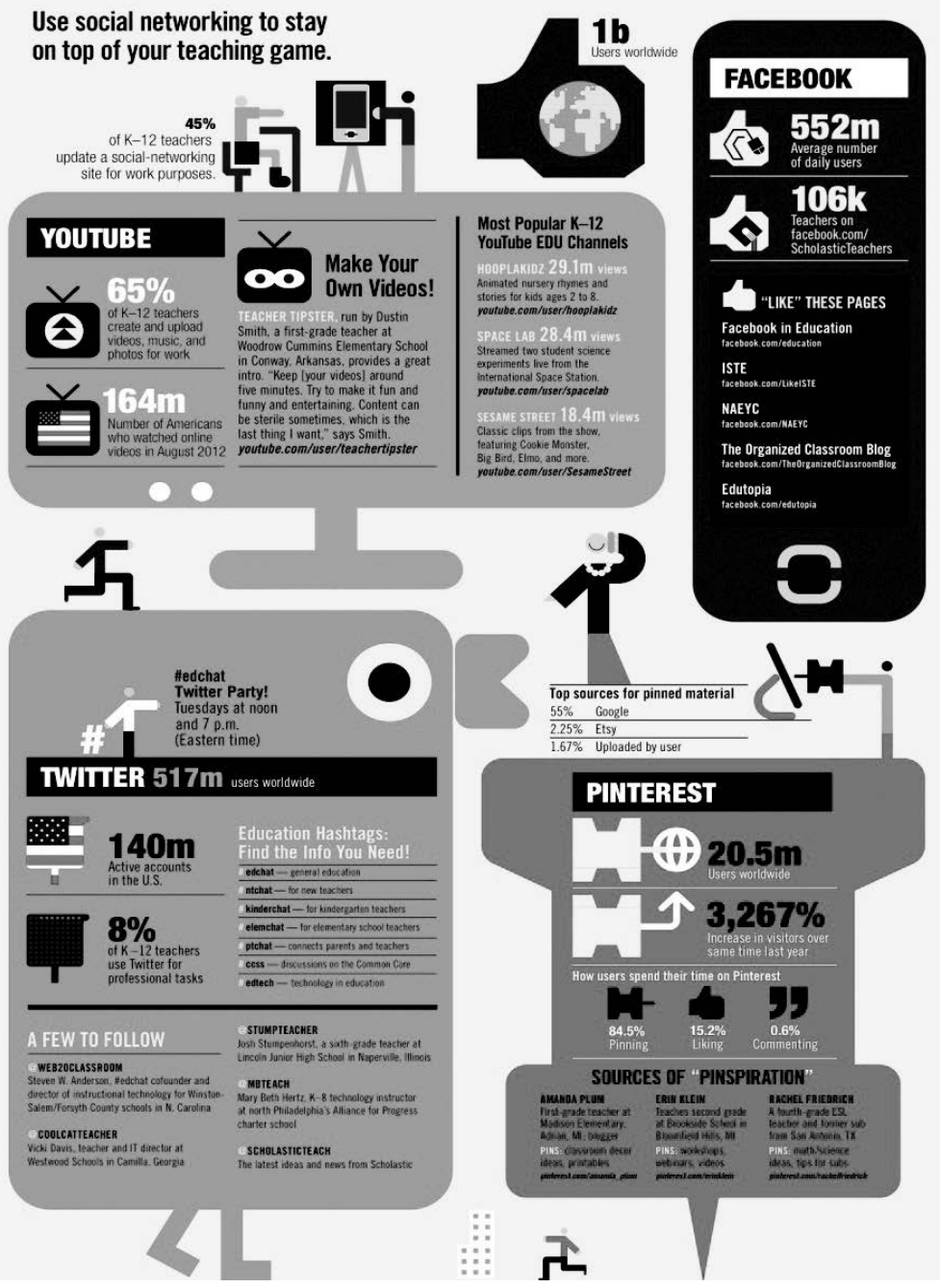

Fuente: <https://ar.pinterest.com/pin/204984220511127643/?p=true>.

\footnotetext{
${ }^{14}$ Edudemic (2012). Social media for teachers [vía Pinterest].
} 
La digitalización de los contenidos escolares facilitará el acceso a los mismos desde cualquier parte. Nos despediremos de las pesadas mochilas, y se abaratará el alto coste para las familias que ya tenían las ediciones impresas de los libros de texto, pero no conseguirá cambiar la metodología docente o reducir la brecha digital. Para esto hace falta mucho mas trabajo, aunque la creación de una buena infraestructura tecnológica es el primer capítulo de esta historia.

La escuela 2.0 se consigue a través del apoyo y de la comprensión individual de las necesidades del alumno. Ayudarle a través de programas específicos con aquellas asignaturas o temas con los que tenga una mayor dificultad es lo que convierte a una escuela tradicional en una escuela 2.0, una escuela interactiva. Antes no había medios para disponer de un profesor dedicado a tratar a sus alumnos individualmente, pero, gracias a los soportes digitales, esto es posible, ya que cuentan con sus propios sistemas de evaluación y corrección, explicando los fallos básicos y llevando a los alumnos a la comprensión directa del error. El profesor se convertirá en un guía que ayudará a los alumnos a alcanzar los conocimientos a través de los mejores medios y canales. Estos mismos sistemas pueden comunicar al docente, a través de informes, los avances y los fallos de cada alumno, y así facilitarle la labor de evaluación en cada caso, consiguiendo una retroalimentación adecuada para cada individuo. Recordemos que una parte fundamental en el trabajo de los docentes es ofrecer el feedback adecuado en cada situación para ayudar a avanzar y mejorar a cada estudiante.

La formación del profesorado es fundamental también para producir este cambio en la escuela, pero no se trata solo de formación a la hora de utilizar tecnología, sino de una formación intensa acerca del uso de los métodos docentes informáticos. Al igual que se hacía con los medios físicos, siempre se ha necesitado una buena formación docente para conseguir una enseñanza de calidad. El docente debe conocer todas las posibilidades de cada medio, de cada programa, de cada red social, etc., para aprovechar las ventajas y evitar los inconvenientes de los mismos. Es importante tener ganas de innovar y de aplicar las mejoras existentes. No todos los docentes han de ser creativos e innovadores, pero sí deben evolucionar e intentar transformar su estilo de docencia y enfocarlo hacia la educación 2.0. Las oportunidades ofrecidas por la escuela 2.0 son prácticamente infinitas, pero se necesita un amplio conocimiento del contexto estudiantil y tecnológico para aplicarlas adecuadamente, es decir, una formación de habilidades y competencias fundamentales.

El uso de redes sociales para la formación del profesorado es una de las opciones que nos aporta el nuevo contexto educativo, y la característica principal del uso que los profesores han hecho de las redes sociales para formarse es que ha sido autónomo y, muchas veces, por decisión propia, es decir, apenas sin darse cuenta de ello. Gracias a ellas, los docentes están al día con los datos y pueden acceder de una manera rápida y directa a fuentes de información en las que confían ellos o personas de su entorno, es decir, fuentes de calidad, algo muchas veces difícil de encontrar entre la vorágine de información disponible en internet.

El alumnado también necesita experimentar un cambio. La enseñanza 2.0 es cooperativa, comunicativa y participativa; fomenta la toma de decisiones, la puesta en común de ideas, la resolución de problemas en grupo y de forma individual. Se trata de una educación basada en el diálogo entre profesores y alumnos; en que los mismos estudiantes conforman su propia educación y están totalmente inmersos en ella, lo cual puede conseguirse a través de la interactividad, del uso de videojuegos, de webquest y de redes sociales que faciliten la mutua comunicación y fomenten el interés del alumnado.

Una escuela 2.0 se caracteriza por compartir la información entre alumnos y profesores. Especialmente los segundos son aquellos que deben encargarse de seleccionar la información adecuada y de enseñar a sus alumnos cómo hacer uso de ella.
Una escuela 2.0 se caracteriza por compartir la información entre alumnos y profesores. Especialmente los segundos son aquellos que deben encargarse de seleccionar la información adecuada y de enseñar a sus alumnos cómo hacer uso de ella 


\section{CASOS DE ÉXITO}

Hay muchos casos de aplicación de las nuevas tecnologías, como las redes sociales y los blogs, en la enseñanza. Vamos a referenciar brevemente algunos de ellos:

- El vídeo viral Velaske, yo soi guapa?, con más de 7 millones de visualizaciones desde noviembre de 2017, fue definido por su autor como una forma de acercar a los jóvenes a la historia del arte. Nada nuevo: en 2009 dos chicas hawaianas, Amy Burvall y Herb Mahelona, revolucionaron la forma de enseñar historia con una serie de vídeos musicales virales en su canal History Teachers de YouTube.

- El proyecto TwHistory, en el que profesores y alumnos tuitean en tiempo real el acontecimiento histórico que quieren tratar, dando de alta a los personajes protagonistas.

- Verbcast, pequeña empresa dedicada a crear contenido didáctico, fundada por el profesor de idiomas escocés Mark Pentleton. Fue pionera al utilizar podcasts (grabaciones de audio) que enseñan los verbos franceses usando técnicas de relajación. El segundo proyecto del profesor, Coffee Break Spanish, abordó el aprendizaje del castellano. Y el tercero, Radiolingua, ofrece podcasts gratuitos y de pago que enseñan casi todos los idiomas del mundo.

- Por su parte, el servicio de radiodifusión internacional de Alemania, Deutsche Welle, creó un grupo en Facebook orientado al aprendizaje del alemán, iniciativa que clonaron French Language o Tu Inglés.

- El profesor de origen hispano Enrique Legaspi, en una escuela de Los Ángeles, fue pionero en emplear Twitter en sus clases, obteniendo resultados excelentes con estudiantes rezagados y permitiéndole conocer mucho mejor a sus alumnos.

- Twiducate es una de las primeras plataformas que permitían a los profesores crear redes sociales privadas para sus cursos o clases para compartir información, colgar las tareas o llevar a cabo proyectos con sus alumnos.

- El proyecto Fugleflicks, desarrollado sobre la plataforma Wikispaces, consiste en un espacio creado por Tricia Fuglestad, una profesora de arte de Illinois, en el que profesores y alumnos suben sus vídeos para compartirlos en la red.
- RetoDualiza es una iniciativa llevada a cabo por la Fundación Bankia por la Formación Dual, en colaboración con la Fundación Bertelsmann, la Alianza por la FP Dual y la Cooperativa Gredos San Diego. A través de un concurso, los centros presentan proyectos desde los que se promueva la iniciativa emprendedora. Además se ofrecen a través de su plataforma sesiones de mentoring online para la puesta en marcha de los proyectos.

- El Blog de Iniciativa Emprendedora, creado por la profesora Blanca Cañamero, del centro Campo Charro en Salamanca, consigue el objetivo de que sus alumnos se interesen de una forma práctica, elaborando actividades atractivas.

- Junior Achivement. Esta organización no gubernamental internacional promueve, a través de las distintas redes sociales en la que está presente, información útil para el desarrollo del espíritu emprendedor en las distintas etapas educativas, desde primaria hasta la universidad.

- \#Emprendumooc. Se trata de un MOOC (massive open online course), ofrecido por el Instituto Nacional de Tecnologías Educativas y de Formación del Profesorado (INTEF) del Ministerio de Educación y Formación Profesional, para trabajar el sentido de la iniciativa y la competencia emprendedora, que tiene su prolongación en Twitter a través del hashtag que da título al curso.

- Proyecto Empresarial 2.0. Una de las iniciativas más exitosas, llevada a cabo, desde un instituto de educación secundaria de Consuegra (Toledo), por el profesor Pablo Peñalver y que se inició en el curso 2008-2009. A través de su blog y de las redes sociales ofrece distintos recursos para fomentar la cultura emprendedora entre los jóvenes y se ha convertido en una referencia en España

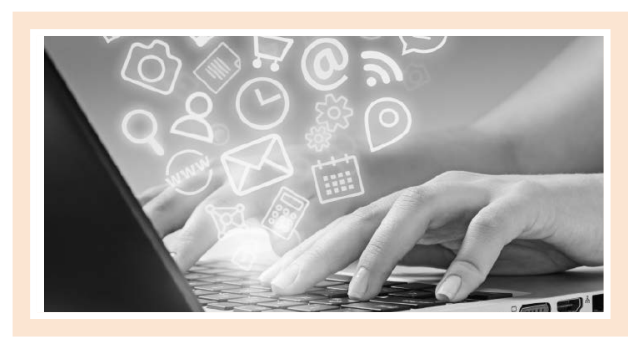




\section{CONCLUSIÓN: CÓMO FOMENTAR LA CULTURA EMPRENDEDORA}

Como afirma García Figueroa (2011), maestra de educación infantil en el centro de educación infantil y primaria Virgen de la Cabeza, de Campillo de Arenas (Jaén), «emprender es un valor que debe fluir en todos los rincones de la sociedad... pero muy especialmente en la educación...».

Tras analizar todos estos casos de éxito, vemos clara la relación entre ellos y el desarrollo del espíritu emprendedor entre los jóvenes. Cuanto más se estimulen sus capacidades de interacción, creatividad, toma de decisiones o resolución de problemas, menos miedo tendrán, en general, a exponer sus ideas y llevarlas a cabo.

Las nuevas tecnologías aplicadas a la educación permiten y fomentan el desarrollo de estas capacidades, así como motivan al alumnado, que se siente más identificado dentro de las clases y dentro del contexto en el que se mueve, el cual se parece más a una sociedad 2.0 como la actual y en la que ellos crecen y se desarrollan.

La educación es una de las claves del desarrollo económico de un país y es fundamental que esté orientada a fomentar el espíritu activo y emprendedor de los jóvenes. Asimismo, ayuda a desarrollar capacidades en los alumnos que podrán ayudarles a lo largo de sus carreras profesionales, bien decidan emprender o no. Es de alta importancia determinar cómo aplicar este cambio necesario en la enseñanza para promover el espíritu emprendedor en la docencia.

Es preciso cambiar la forma de educar, es decir, han de dejarse a un lado las técnicas de educación tradicionales, que se caracterizan por el abuso de la clase magistral, la clara falta de diálogo entre profesores y alumnos, un sistema en el que se penalizan los errores, en el que el profesor solo aporta respuestas y no ayuda a que el alumno las encuentre por sí mismo, donde el profesor es el protagonista de la enseñanza y en el que el grupo no trabaja unido y los objetivos de aprendizaje vienen impuestos por los docentes, sin posibilidad de retroalimentación positiva.

Para implantar este nuevo estilo de enseñanza que buscamos, hay que terminar con esta visión de la educación unidireccional. Para esto, la propia educación ha de ser innovadora, flexible y que fomente la proactividad entre sus alumnos; ha de ser moderna, que este al día de las nuevas tecnologías y que fomente el trabajo en equipo. Las claves están en facilitar el acceso a la información por parte del alumnado, formar en capacidades emprendedoras, como la creatividad, la tolerancia al fracaso o la frustración (ver el fracaso como algo positivo, de lo que se aprende), la innovación, el trabajo colectivo, etc., favoreciendo así la motivación de los alumnos ante el planteamiento de cualquier tarea y durante el desarrollo de la misma.

El estilo educativo emprendedor se caracteriza por que el profesor genera preguntas que los alumnos se ven obligados a resolver por sí mismos, se centra en desarrollar un modo de aprendizaje práctico, en recibir una ecuación multidisciplinar; el grupo trabaja de forma colaborativa y se apoya en el profesor. La introducción de las TIC en la educación, y la posibilidad de un feedback permanente y accesible, se aprende mediante la práctica, dejando a un lado la memorización clásica. Se destierra el miedo al fracaso y, lo más importante, se potencia la interacción entre alumnos y profesores, es decir, la existencia de un diálogo permanente.

Se busca favorecer que sean los alumnos los que se responsabilicen de sus decisiones, de sus deberes y de sus compromisos, de modo que desarrollen su iniciativa personal y su autonomía a la hora de trabajar, sin olvidarse de inculcarles que son responsables de las decisiones que han tomado y de los errores que las mismas conlleven.
La educación es una de las claves del desarrollo económico de un país y es fundamental que esté orientada a fomentar el espíritu activo y emprendedor de los jóvenes 


\section{BIBLIOGRAFÍA}

Álvarez Cano, F. (2017). Reputación social. Programa directivo de innovación y tecnología bancaria. Instituto de Estudios Bursátiles.

Artero Balaguer, N. (2011). La interacción como eje de aprendizaje en las redes sociales. Educaweb. Recuperado de <http://www.educaweb.com/noticia/2011/01/31/ interaccion-como-eje-aprendizaje-redes-sociales-14570.html> (consultado el 2 de febrero de 2018).

Aviram, R. (2002). ¿Conseguirá la educación domesticar a las TIC? II Congreso europeo de TIC en la educación y la ciudadanía, 26, 27 y 28 de junio de 2002. Barcelona.

Bayne, S. y Ross, J. (2007). The «digital native» and «digital immigrant». A dangerous opposition. Annual conference of the Society for Research into Higher Education. Recuperado de <http://www.malts.ed.ac.uk/staff/sian/ natives_final.pdf> (consultado el 24 de marzo de 2018).

Bennet, S. y Maton, K. (2010). Beyond the «digital natives» debate: towards a more nuanced understanding of students' technology experiences. Journal of Computer Assisted Learning, 26, 321-331.

Calvo, E. (2005). Las tecnologías de la información en las empresas españolas: situación 2004. España: Colección EOI Empresas/EOI Escuela de Negocios.

Checa Garcia, F. (2010). Creación y transferencia de conocimiento mediante la utilización de tecnologías Web 2.0: blogs y microblogs en el ámbito educativo. (Tesis doctoral). Recuperado de <https://es.slideshare.net/ fcheca/defensa-de-tesis-de-fernando-checa-garca> (consultado el 24 de marzo de 2018).

Delle Femine, L. (25 de junio de 2015). La crisis, ¿el motor de las startups? El País. Recuperado de <https://elpais.com/economia/2015/06/23/actualidad/1435074253_488183.html> (consultado el 13 de enero de 2018).

García Figueroa, T. (2 de mayo de 2011). Fomento de la cultura y el espíritu emprendedor en el actual sistema educativo. Educaweb. Recuperado de <https:// www.educaweb.com/noticia/2011/05/02/fomento-cultura-espiritu-emprendedor-actual-sistema-educativolejos-ser-tratamiento-exclusivo-eso-ensenanza-secundaria-postobligatoria-ambito-universitario-4736/> (consultado el 5 de abril de 2018).
García, N. (22 de enero de 2014). Roque de las Heras Miguel: «Nunca hemos tenido una cultura emprendedora». El Economista. Recuperado de <http:/l www.eleconomista.es/ecoaula-emprendedores/noticias/5477631/01/14/Nunca-hemos-tenido-una-culturaemprendedora.html> (consultado el 5 de abril de 2018).

Global Education Forum (2010). Educar en la creación y gestión de la identidad digital de los menores.

Inmediaciones (26 de septiembre de 2017). Big data $y$ educación: oportunidades para el desarrollo. Recuperado de <http://inmediaciones.org/big-data-y-educacion-oportunidades-para-el-desarrollo/> (consultado el 5 de abril de 2018).

Lara, T. (2009). El papel de la universidad en la construcción de su identidad digital. RUSC. Revista de Universidad y Sociedad del Conocimiento. Monográfico Cultura Digital y Prácticas Creativas en Educación, 6(1).

Ley orgánica 8/2013, de 9 de diciembre, para la mejora de la calidad educativa (BOE núm. 295, de 10 de diciembre).

Marqués, P. (2013). Impacto de las TIC en la educación: funciones y limitaciones. 3 c TIC: Cuadernos de Desarrollo Aplicados a las TIC, 2(1).

Martínez, J. (2004). El papel del tutor en el aprendizaje virtual. UOC. Recuperado de <http://www.uoc.edu/ dt/20383/index.html> (consultado el 4 de marzo de 2018).

Murillo, J. L. (19 de septiembre de 2010). Una propuesta para los centros educativos en la sociedad digital: comunidades educativas digitales. Aula Libre.

Núñez, V., Menor, J. y Baeza, F. (Coords.) (2014). Educación digital y cultura de la innovación. Madrid: Cotec.

Orden ECD/65/2015, de 21 de enero, por la que se describen las relaciones entre las competencias, los contenidos y los criterios de evaluación de la educación primaria, la educación secundaria obligatoria y el bachillerato (BOE núm. 25, de 29 de enero).

Piscitelli, A. (8 de septiembre de 2011). Periódico Escuela, 3.913. Editorial Wolters Kluver.

Prensky, M. (2001). Digital natives, digital immigrants. On the Horizon, 9, 1-6.

Segovia Garcia, N. (31 de enero de 2011). Las redes sociales: un reto para la escuela del siglo XXI. Educaweb. 